\title{
Effects of plant tissue factors on the acceptance of four greenhouse vegetable host plants by the greenhouse whitefly: an Electrical Penetration Graph (EPG) study
}

\author{
Hong LEI ${ }^{1,2,3}$, Joor C. vaN LENTEREN ${ }^{1 *}$ and Ru M. XU ${ }^{2}$ \\ ${ }^{1}$ Laboratory of Entomology, Wageningen University, 6700 EH Wageningen, The Netherlands; \\ e-mail: joop.vanlenteren@users.ento.wau.nl \\ ${ }^{2}$ Department of Biology, Beijing Normal University, Beijing 100875, P.R. China \\ ${ }^{3}$ Current address: ARLDN, University of Arizona, Tucson, AZ 85721-0077, USA
}

Key words. Trialeurodes vaporariorum, whitefly, electrical penetration graph, host-plant acceptance, host-plant quality, resistance factors

\begin{abstract}
A combination of biological control and host-plant resistance is needed to control greenhouse whitefly, Trialeurodes vaporariorum (Westwood). The high level of susceptibility of several host plants to whitefly, based on their performance on these plants, is well documented. These studies only provide information on the overall host-plant acceptance by whiteflies. Here, we use a method that allows an examination of the different tissue layers in the overall acceptance. The effects of plant tissue factors on whitefly probing profiles were monitored using the electrical penetration graph (EPG) method. The EPGs of whitefly originating from a culture on glasshouse cucumber, were recorded for 8 hours on sweet pepper, tomato, gerbera and cucumber plants produced in a glasshouse. On sweet pepper the graphs showed that whitefly made many short probes, had long xylem phases, short phloem phases, and the shortest duration of first probes. An opposite probing profile was found on cucumber: longer probes, shorter xylem phases, fewer phloem phases but of longer duration, and longer first probes. The values of these parameters for gerbera and tomato were intermediate. Whiteflies encountered the greatest stimulation or the least resistance in the tissues of cucumber, and the least stimulation or the greatest resistance in the tissues of sweet pepper. Rejection of host plants probably occurred before the phloem tissue was reached, as the probes prior to a whitefly leaving a host plant were so short that the stylets cannot have reached the phloem. But phloem factors also determine host-plant rejection, as phloem probing on sweet pepper - a poor host plant - was much shorter than on the other host plants. Resistance factors seem, therefore, to be located both in the epidermis/mesophyll and in the phloem. We hypothesize that the factors encountered by whitefly in the different tissue layers during probing contribute to the acceptance or rejection of a host plant. Based on the performance of whitefly on these plants, which is also reflected in the values of the EPG parameters, the order of acceptance ranked from high to low is cucumber $>$ tomato = gerbera $>$ sweet pepper.
\end{abstract}

\section{INTRODUCTION}

The greenhouse whitefly, Trialeurodes vaporariorum (Westwood), is a serious pest of vegetables and ornamentals growing in greenhouses and outside throughout the world (van Lenteren et al., 1992). This insect attacks more than 860 plant species from 469 genera and 121 families (Xu, 1994). Whitefly cause (a) direct damage by phloem sap ingestion, (b) indirect damage by transmitting plant viruses and other diseases (Cohen, 1990) and (c) decreased photosynthesis as a result of sooty moulds that develops on the honeydew excreted by the insect (Vet et al., 1980). One way of controlling whiteflies is through host-plant resistance (de Ponti et al., 1990). Complete host-plant resistance to insects has been found, and is employed against several insect pests, but is seldom permanent. Partial resistance against whitefly has been found in several plant species, and is demonstrated by differences in the acceptance by $T$. vaporariorum of a number of greenhouse crops and cultivars (van Lenteren \& Noldus, 1990). Partial resistance tends to be more durable, which is an advantage for the development of sustainable crop protection. In addition, partial resistance may augment the effect of biological control with the parasitoid Encarsia formosa Gahan (van Lenteren \& de Ponti, 1990), a natural enemy which is widely applied in commercial greenhouse vegetables (van Lenteren \& Woets, 1988; van Lenteren et al., 1996). However, introducing partial resistance into commercial crops requires sophisticated testing methods during the breeding process and the lack of methods for doing this accounts for the relative shortage of varieties resistant to whitefly (de Ponti et al., 1990; Romanow et al., 1991).

In order to develop such a test and to understand the mechanisms of partial resistance expressed as different degrees of acceptance by whiteflies, we embarked upon a study of the effect of plant acceptance on host selection by $T$. vaporariorum. A correlation between host-plant acceptance and host-plant quality of different plant species for the greenhouse whitefly has been established for a range of host plants (van Lenteren \& Noldus, 1990). The rank order of plant acceptance and plant quality is the same and reads from high to low as: egg plant > cucumber $=$ gherkin $=$ melon $>$ gerbera $=$ tobacco $>$ bean $=$ tomato $>$ sweet pepper. Most experiments to determine

\footnotetext{
* Corresponding author.
} 
the acceptance level of a host plant consist of confining whitefly on the host plants followed by observation of the behaviour of whitefly and subsequently counting the number of whiteflies on the plants after certain intervals. Experiments on host-plant quality consisted of measuring fecundity, adult longevity, immature mortality and developmental time. However, such experiments do not elucidate the mechanisms underlying host-plant acceptance.

The factors that affect the acceptance of host plants by whitefly have not yet been clarified. Nevertheless, it is known that whitefly are not capable of selecting a host plant before landing and probing (van Lenteren \& Noldus, 1990; Xu, 1994). Van Lenteren and Noldus (1990) postulated that cues in tissues that are encountered before the phloem vessels may be responsible for the whitefly's preference for certain species of host plants, because they usually reject an unsuitable plant within a few minutes, a time span in which the insects could not have reached the phloem tissue (Janssen et al., 1989). The effects of leaf cuticle and hairiness on host-plant selection by other species of whitefly were studied by Butler et al. (1988), Walker (1988), and Walker \& Zareh (1990). Their data indicate that factors on the leaf surface influence host-plant selection by whitefly. Data on a possible relation between whitefly preference and the interior features of a host plant are rare (Walker, 1985; van Lenteren \& Woets, 1988; Byrne \& Bellows, 1991). With the data available we cannot distinguish the contribution of the different tissues to host-plant acceptance (Zhang et al., 1987; Xu \& Zhang, 1991; Ma et al., 1992).

For a better understanding of the role of different tissues in plant acceptance we require detailed information on the probing behaviour of whitefly. An electrical system that monitors probing, the electrical penetration graph method (EPG) (Tjallingii, 1988), allows us to obtain such information. Recently, the probing behaviour of whitefly adults and larval stages was studied (Janssen et al., 1989; Lei et al., 1996). In adults, the following probing phases can be distinguished: the pathway phase (indicating intercellular probing), the xylem phase (indicating water uptake) and the phloem phase (indicating phloem-sap ingestion).

In this paper, we compare the probing behaviour of whitefly on four plants with known differences in acceptance levels (van Lenteren \& Noldus, 1990), in an attempt to determine the role of tissue factors in the probing behaviour of whitefly.

\section{MATERIAL AND METHODS}

\section{Plants and whiteflies}

The following plants were used: Cucumis sativus L. (cucumber) cv. Changchun Michi, Gerbera jamesonii Hook (gerbera) $\mathrm{cv}$. Fame, Lycopersicon esculentum L.(tomato) cv. Moneydor and Capsicum annuum L.(sweet pepper) cv. Tisana. The plants were grown in a glasshouse at $18-22^{\circ} \mathrm{C}$ and a16L : $8 \mathrm{D}$ photoperiod and seedlings with 5-6 leaves were used in experiments. Counting from the top, the first three leaflets of the $2^{\text {nd }}$ or $3^{\text {rd }}$ leaf of tomato, the $2^{\text {nd }}$ pair of leaves of sweet pepper and the $2^{\text {nd }}$ or $3^{\text {rd }}$ leaf of cucumber were used as the probing and feeding substrates for whitefly. Whitefly were reared on cucumber plants and kept in separate cages in glasshouse compartments under the conditions decribed above. Three-day-old females were used in the experiments. Whitefly individuals were used once. Each plant was used for maximally two EPG recordings. Twenty-five whiteflies were recorded on each plant species.

\section{EPG recording}

The EPGs were recorded with a DC system with an input resistance of $10^{\circ} \mathrm{Ohm}$. Each recording lasted 8 hours. The plant, whitefly and amplifier were placed in a Faraday cage to reduce the electronic noise. Before the start of an EPG recording, a female whitefly was immobilized by cooling it in a freezer for about 5 seconds. Then it was placed onto a vacuum device, the white wax powder cleaned from its body with the aid of a fine brush, and a gold wire ( $2 \mathrm{~cm}$ long, $10 \mu \mathrm{m}$ in diameter) attached to its dorsum with silver paint. The EPG signal was first recorded on a tape recorder and then transferred to a computer hard disk. The data were analyzed subsequently with STYLET 2.0. software. Fourteen EPG parameters related to the pathway phase ( $\mathrm{C}$ waveform, $\mathrm{F}$ waveform and potential drops), xylem phase ( $G$ waveform) and phloem phase (E waveform) were extracted from each recording and compared between the plants (Table 1). The mean number and total duration of the probes, pathway phases, xylem phases and phloem phases were measured as general parameters (Parameters 2-7, 10-13, Table 1). The duration of the $1^{\text {st }}$ probe was measured to analyse the effects of leaf surface factors on host-plant acceptance (Parameter 1, Table 1). Two parameters, i.e. (1) the number of probes before the $1^{\text {st }}$ phloem phase, and (2) the time needed to reach the $1^{\text {st }}$ phloem phase from the start of a probe, were measured to determine whether mesophyll factors influence the pathway of probing of whitefly (Parameters 8-9, Table 1). Finally, the percentage of whitefly that reached the phloem phase on the different plants was compared (Parameter 14, Table 1).

In addition to the analysis of the mean values of these EPG parameters, a more detailed hour-by-hour analysis was carried out to further elucidate the acceptance levels of the host plants. The number of probes in each hour of the 8 -h recordings on four plant species was counted and plotted. The changes in this parameter were then compared between the plants (Fig.1).

\section{Statistics}

The non-parametric Kruskall-Wallis method followed by multiple comparison was used to test the significance within groups and the Mann-Whitney $U$ test was used to test for pairwise differences. Both methods were carried out with the STATGRAPHICS 2.6 software.

\section{RESULTS}

The process of host-plant selection by whitefly consists of a series of consecutive events starting with the first labial contact with the plant surface, followed by stylet penetration through successive tissue layers between the epidermis and the phloem vessel and, ultimately, by feeding on phloem sap. Our experiments have shown that this process can be affected by plant tissue factors. These tissue factors either prolong or reduce the duration of the probing activities that occur in these particular tissues. The parameters shown in Table 1 represent the probing activities of whitefly at the leaf surface, and in the mesophyll, xylem or phloem.

The whitefly showed the shortest duration of the $1^{\text {st }}$ probes on sweet pepper and the longest on cucumber 
TABLE 1. Comparison of EPG parameters of whitefly probing on four species of plants. All times are in minutes, all numbers are averages per 8 hour observation period. Values in one row followed by different letters differ significantly $(P<0.05)$.

\begin{tabular}{|c|c|c|c|c|c|c|c|c|}
\hline & cucumber & & tomato & & gerbera & & sweet pepper & \\
\hline 1 Time of 1st probe & $4.3 \pm 2.1$ & a & $1.5 \pm 0.2$ & $\mathrm{~b}$ & $2.9 \pm 1.2$ & a & $1.3 \pm 0.3$ & $\mathrm{~b}$ \\
\hline 2 Number of probes & $23.8 \pm 2.6$ & a & $48.0 \pm 4.2$ & $\mathrm{~b}$ & $41.2 \pm 5.7$ & $b$ & $70.8 \pm 5.2$ & $\mathrm{c}$ \\
\hline 3 Total time spent probing & $420.1 \pm 9.3$ & a & $350.8 \pm 12.8$ & a & $346.8 \pm 16.1$ & a & $373.2 \pm 10.5$ & a \\
\hline 4 Number of pathway phases (C) & $28.0 \pm 2.8$ & $\mathrm{a}$ & $52.9 \pm 4.1$ & $\mathrm{~b}$ & $44.1 \pm 5.6$ & $\mathrm{~b}$ & $74.1 \pm 6.2$ & $\mathrm{c}$ \\
\hline 5 Total time spent in C & $183.1 \pm 18.6$ & $\mathrm{a}$ & $203.0 \pm 12.4$ & a & $184.8 \pm 15.6$ & a & $244.1 \pm 12.1$ & a \\
\hline 6 Number of phloem phases (E) & $2.5 \pm 0.5$ & a & $2.6 \pm 1.2$ & a & $2.8 \pm 0.4$ & a & $3.0 \pm 1.3$ & a \\
\hline 7 Total time spent in $\mathrm{E}$ & $201.3 \pm 9.5$ & a & $104.3 \pm 16.6$ & $\mathrm{~b}$ & $103.5 \pm 21.9$ & $\mathrm{~b}$ & $69.4 \pm 8.7$ & $\mathrm{c}$ \\
\hline 8 Number of probes before 1 st $\mathrm{E}$ & $28.1 \pm 3.4$ & a & $38.7 \pm 4.7$ & a & $32.8 \pm 5.1$ & a & $132.1 \pm 7.0$ & b \\
\hline 9 Time to 1 st $\mathrm{E}$ within a probe & $34.5 \pm 3.1$ & a & $27.2 \pm 2.9$ & $a b$ & $25.6 \pm 2.4$ & $\mathrm{~b}$ & $25.8 \pm 3.5$ & $b$ \\
\hline 10 Number of $F$ patterns & $0.9 \pm 0.1$ & a & $1.5 \pm 0.3$ & a & $1.8 \pm 0.5$ & a & $2.2 \pm 0.6$ & a \\
\hline 11 Total time spent in F & $51.2 \pm 12.0$ & $\mathrm{bc}$ & $20.5 \pm 4.5$ & a & $28.7 \pm 8.8$ & $a b$ & $37.2 \pm 7.1$ & bc \\
\hline 12 Number of xylem phases (G) & $1.5 \pm 0.2$ & a & $1.2 \pm 0.2$ & a & $1.5 \pm 0.2$ & a & $1.4 \pm 0.3$ & a \\
\hline 13 Total time spent in $\mathbf{G}$ & $35.5 \pm 16.5$ & a & $55.8 \pm 8.7$ & a & $60.2 \pm 9.4$ & a & $89.4 \pm 18.2$ & $\mathrm{~b}$ \\
\hline 14 Whiteflies showing phloem phase (\%) & 76 & & 72 & & 67 & & 25 & \\
\hline
\end{tabular}

(Parameter 1). The 8-h recordings revealed that whitefly made the highest number of probes on sweet pepper and the lowest on cucumber, and intermediate numbers on gerbera and tomato (Parameter 2). However, the total duration of the probes was approximately equal on all four plants (Parameter 3). Similar phenomena were observed during the pathway phases: significant differences were detected for the number of pathway phases but not for the total duration (Parameters 4 and 5). The number of probes prior to the $1^{\text {st }}$ phloem phase (Parameter 8 ) was highest on sweet pepper and lowest on cucumber. Nevertheless, the whitefly took less time to reach the phloem phase on sweet pepper (Parameter 9) than on cucumber. The values of this parameter on gerbera and tomato were close to that on sweet pepper.

Seventy-six percent, $67 \%, 72 \%$ and $25 \%$ of the 8 -h recordings showed a phloem phase for the whitefly probing cucumber, gerbera, tomato and sweet pepper, respectively (Parameter 14). Whitefly had the shortest duration of phloem phase on sweet pepper and the longest on cucumber (Parameter 7). The total duration of phloem phases did not differ greatly between gerbera and tomato.

No significant differences were found between plant species in the number of $\mathrm{F}$ and $\mathrm{G}$ waveforms. Whitefly had the longest duration of $G$ waveforms on sweet pepper and the longest duration of $\mathrm{F}$ waveforms on cucumber (Parameters 10-13).

Figure 1 shows the changes in the number of probes that occurred in each hour of the 8-h recordings on the four plant species. In general, in the course of 8 -h recording, whitefly showed a decrease in the number of probes. This reduction was highest on sweet pepper and lowest on cucumber. Significant differences in the number of probes were observed on sweet pepper and cucumber (Fig.1a). They also made significantly more probes on sweet pepper compared with gerbera and tomato, but only during the first 3 or 4 hours, respectively (Fig.1b,c). The differences in the time spent probing on tomato and cucumber or gerbera were not large, though significant differences were sometimes detected (Fig.1d,e). No significant differences were found in the probing behaviour on gerbera and cucumber (Fig.1f).

\section{DISCUSSION}

Previous studies on the performance of whitefly on host plants have shown a consistent relation between hostplant acceptance and host-plant quality. For the four host plants used in this study the host-plant acceptance order from good to poor is cucumber $>$ tomato $=$ gerbera $>$ sweet pepper (van Lenteren \& Noldus, 1990). The results of this study confirm this and the EPG results provide additional information on the contribution of each tissue layer to the acceptance of a host plant.

Information on the leaf surface may affect an insect's probing behaviour at the initial stage. Epicuticular wax composition (Ma et al., 1992) and thickness of the epidermal cuticle (Walker, 1988) may influence host-plant acceptance. Whitefly on sweet pepper exhibit many short probes (Parameters 2 and 3, Table 1), which could result from the presence of a deterrent or the lack of a stimulant on the leaf surface. Whitefly probed longest on the most suitable host plant (cucumber), and shortest on the poorest host plant (sweet pepper) (Parameter 1, Table 1). Again, this indicates the presence of a deterrent or the lack of a stimulant on the surface of sweet pepper leaves. We speculate that the similarly short first probe on tomato (a better host plant than sweet pepper) is the result of the high hair-density on tomato leaves, with maximum counts of 1900 hairs $/ \mathrm{cm}^{2}$, whereas sweet pepper leaves are hairless (van Lenteren \& de Ponti, 1990). With the EPG technique it is not possible to separate the effect of deterrents or stimulants on the epidermis from those in the mesophyll, but behavioural observations show that free, nonwired whitefly reject sweet pepper after probes that last less than one minute (Lei et al., 1997). Within such a short time, they will not have penetrated far beyond the epidermis, and the presence of deterrents or lack of stimu- 

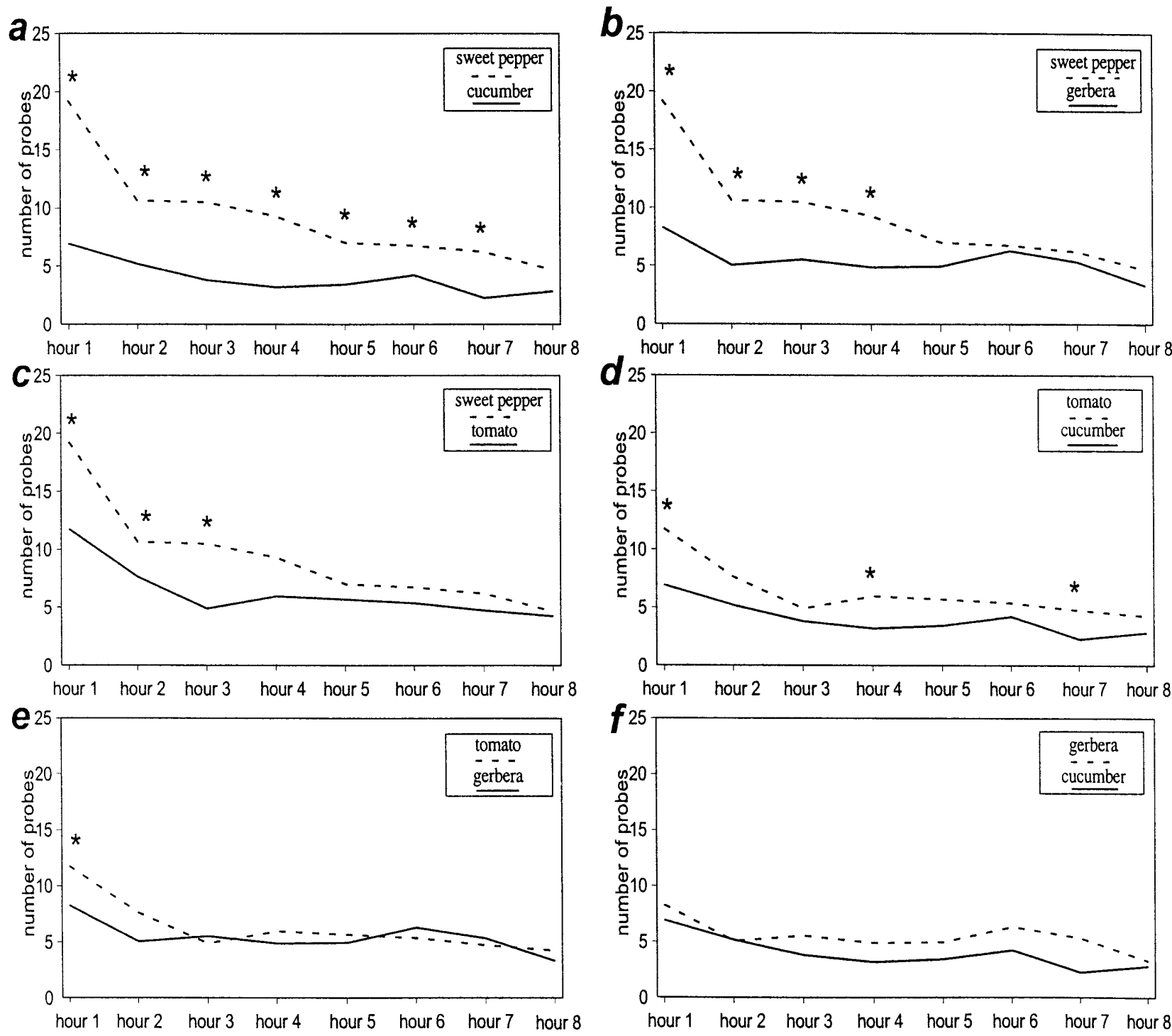

Fig. 1 Pairwise per-hour-comparison of the number of probes made by whitefly on four plant species over the course of an $8 \mathrm{~h}$ recording. The asterisk indicates significance at 0.05 level (Mann-Whitney $U$ test).

lants in the leaf epidermis and/or mesophyll of sweet pepper obviously prevented them from probing further.

Mechanical structures and chemical composition of the mesophyll cell walls are thought to affect probing (Campbell et al., 1986), but their influence on whitefly cannot be determined from our data. Parameter 9 expresses the time it takes whitefly from the start of a probe to reach the phloem and start feeding. The value of this parameter differed significantly on cucumber and the other host plants, but in a counterintuitive way; whitefly needed significantly more time to reach the phloem on the most suitable host plant cucumber, than on the less suitable host plants (Parameter 9, Table 1).

The number and duration of the $F$ and $G$ waveforms (Parameters 10-13, Table 1) give little information about the effect of mesophyll factors on the probing behaviour. The $\mathrm{F}$ waveform is generally considered to be a measure of the mechanical problems encountered by aphids during stylet penetration (Caillaud et al., 1995). The longest duration of $\mathrm{F}$ waveforms was observed on cucumber and the durations on the other three host plants were similar (Parameter 11, Table 1). Mechanical problems may have caused whitefly to have a long probing pathway on cucumber, but this needs further investigation and the $\mathrm{F}$ waveforms only occurred occasionally. The $G$ waveform represents water ingestion from xylem vessels (Spiller et al., 1990). The duration of the $\mathrm{G}$ waveform is often negatively related to the duration of the $\mathrm{E}$ waveform, probably due to the water stress caused by insufficient phloem feeding (Spiller et al, 1990). This hypothesis is supported by our data: whitefly had the longest duration of $\mathrm{G}$ waveforms on sweet pepper, the poorest host plant, and the shortest duration on cucumber, the best host plant (Parameter 13, Table 1). The values of this parameter were intermediate on gerbera and tomato.

The quality of phloem sap mainly determines the resistance of plants against aphids (e.g. Kimmins, 1989; Montllor \& Tjallingii, 1989; McCauley et al., 1990; van 
Helden \& Tjallingii, 1993; Chen et al., 1997; Lei et al., 1997). In whitefly the number of phloem phases was similar for all host plants (Parameter 6, Table 1). The total time spent in the phloem phase was shortest on sweet pepper and longest on cucumber (Parameter 7, Table 1), and intermediate and similar for gerbera and tomato. So, in addition to factors associated with the epidermis, there are also features of the phloem in sweet pepper that lead to the rejection of this host plant. Normally, non-wired, free ranging adults make very short probes on sweet pepper and leave this plant before they could have reached the phloem. When tethered for an EPG-recording, 25\% of the whitefly showed a phloem phase on sweet pepper, but free range whitefly usually do not 'encounter' the phloem based resistance factors in sweet pepper. To identify the phloem based resistance factors, it is necessary to determine the honeydew composition of whitefly fed on a variety of host plants, but such studies have seldomly been performed (Lei \& Xu, 1993).

The percentage of whitefly showing the phloem phase (Parameter 14, Table 1) is lowest on sweet pepper and highest on cucumber. The general conclusion that cucumber is preferred to sweet pepper by whitefly, is supported by most of the EPG parameter values (Parameters 1-8 and 10-13, Table 1). In general, on unsuitable host plants, whitefly display (a) many short probes, most of which do not end up in a vascular bundle; (b) few and short periods of phloem-sap ingestion and (c) long periods of xylem-sap ingestion.

Most of the EPG parameter values for whitefly probing on gerbera and tomato did not differ significantly. Wiring effects may mask the more subtle differences in probing of whitefly on these host plants (Lei et al., 1997). Therefore, the number of probes was compared hour by hour, but no differences were found between tomato and gerbera (Fig.1). The number of probes generally decreases in the course of time, regardless of plant species. However, this phenomenon is most obvious on the least acceptable plant, sweet pepper. Interestingly, the comparison between sweet pepper and gerbera or tomato revealed significant differences during the first 3 or $4 \mathrm{~h}$, respectively. This result indicates that the acceptance of a host plant by whitefly may be modulated by previous experience on that plant, and this modulation can occur within hours. Similar results have been reported previously by van Lenteren \& Noldus (1990) and Lei et al. (1998). When whitefly are transferred from a poor to a good host plant, they accept the good plant more readily (as defined by longer feeding and more oviposition on that plant) than when transferred from a better or equally good host plant (van Lenteren \& Noldus, 1990).

In our experiments we have used vegetables that are specially selected for production in greenhouses. It is generally accepted that crops grown under greenhouse conditions usually have much lower levels of secondary plant substances than when grown in the field (Schoonhoven et al., 1998). Also, the morphological structure and thickness of wax and epidermis layers can differ between greenhouse and field grown crops. Since probing by whitefly is very sensitive to changes in the interior and exterior features of plants, EPG parameters are expected to differ when measured on plants that are grown in field conditions.

The order of host-plant acceptance, both in terms of EPG parameter values (this paper) and behavioural/performance data (van Lenteren \& Noldus, 1990), indicate that cucumber is the best, tomato and gerbera intermediate and similar, and sweet pepper is the worst host plant for whitefly. This is consistent with experience from commercial greenhouses, where biological control of whitefly is very easy on sweet pepper, successful and easy on tomato and gerbera, but more difficult on cucumber (van Lenteren et al., 1996). Development of partial resistance in cucumber might facilitate more reliable biological control of whitefly on this important greenhouse crop.

ACKNOWLEDGEMENTS. W.F. Tjallingii is thanked for supervising the experiments and for providing all experimental equipment. E. Prado and B. Gabryl are thanked for advice, S. Sütterlin for providing the gerbera plants. The first author was supported by a grant from the Royal Netherlands Academy of Sciences (KNAW) in the framework of a long-term scientific exchange programme between Wageningen University and Beijing Normal University.

\section{REFERENCES}

Butler G.D., Rimon D. \& Henneberry T.J. 1988: Bemisia tabaci (Homoptera: Aleyrodidae): populations on different cotton varieties and cotton stickiness in Israel. Crop Prot. 7 : $43-47$.

Byrne D.N. \& Bellows T.S. 1991: Whitefly biology. Anmu. Rev. Entomol. 36: 431-457.

Caillaud C.M., Pierre J.S., Chaudbet B. \& Pietro J.P. Di 1995: Analysis of wheat resistance to the cereal aphid Sitobion avenae using electrical penetration graphs and flow charts combined with correspondence analysis. Entomol. Exp. Appl. 75: $9-18$.

Campbell B.C., Jones K.C. \& Dreyer D.L.1986: Discriminative behavioral responses by aphids to various plant matrix polysaccharides. Entomol. Exp. Appl. 41: 17-24.

Chen J.Q., Rahb, Y., Delobel B., Sauvion N., Guillaud J. \& Febvay G. 1997: Melon resistance to the aphid Aphis gossypii: behavioural analysis and chemical correlations with nitrogenous compounds. Entomol. Exp. Appl. 85: 33-44.

CoHen S. 1990: Epidemiology of whitefly-transmitted viruses. In: Gerling D. (ed.), Whiteflies: Their Bionomics, Pest Status and Management. Intercept, Andover, pp.211-225.

Helden M. van \& TJallingil W.F. 1993: Tissue localisation of lettuce resistance to the aphid Nasonovia ribisnigri using electrical penetration graphs. Entomol. Exp. Appl. 68: 269-278.

JANSSEN J.A.M., TJALLINGII W.F. \& LENTEREN J.C. VAN 1989: Electrical recording and ultrastructure of stylet penetration by the greenhouse whitefly. Entomol. Exp. Appl. 52: 69-81.

KIMMINS F.M. 1989: Electrical penetration graphs from Nilaparvata lugens on resistant and susceptible rice varieties. Entomol. Exp. Appl. 50: 69-79.

LeI H. \& XU R.M. 1993: Studies on honeydew excretion by greenhouse whitefly, Trialeurodes vaporariorum (Westw.) on its host plant, Cucumis sativus. J. Appl. Entomol. 115: 43-51.

Lei H., Tuallingil W.F., Lenteren J.C. van \& Xu R.M. 1996: Stylet penetration by larvae of the greenhouse whitefly on cucumber. Entomol. Exp. Appl. 79: 77-84. 
Lei H., TiallingiI W.F. \& Lenteren J.C. van 1997: Effect of tethering during EPG recorded probing by adults of the greenhouse whitefly. J. Appl. Entomol. 121: 211-217.

Lei H., Tuallingit W.F. \& Lenteren J.C. van 1998: Probing and feeding characteristics of the greenhouse whitefly in association with host-plant acceptance and whitefly strains. Entomol. Exp. Appl. 88: 73-80.

Lenteren J.C. van \& Noldus L.P.J.J. 1990: Behavioral and ecological aspects of whitefly-plant relationships. In: Gerling D. (ed.): Whiteflies: Bionomics, Pest Status and Management. Intercept, UK, pp. 47-89.

Lenteren J.C.van \& Ponti O.M.B. De 1990: Plant-leaf morphology, host-plant resistance and biological control. Proc. $7^{\text {th }}$ Int. Symp. Insect-Plant Relationships. Akademiai Kiado, Budapest. Symp. Biol. Hung. 39: 365-385.

LENTEREN J.C. VAN \& WoETS J. 1988: Biological and integrated pest control in greenhouse. Annu. Rev. Entomol. 33: 239-269.

Lenteren J.C. van, RoERmund H.J.W. van \& SÜtTERLin S. 1996: Biological control of greenhouse whitefly (Trialeurodes vaporariorum): how does it work? Biol. Control 6: 1-10.

Lenteren J.C. van, Benuzzi M., Nicoli G. \& Maini S. 1992 Biological control in protected crops in Europe. In: Lenteren, J.C. van; Minks A.K. \& Ponti O.M.B. de (eds): Biological Control and Integrated Crop Protection: Towards Environmentally Safer Agriculture, Pudoc, Wageningen, The Netherlands, pp. 77-89.

MA W.R., XU R.M. \& Zhang Y. 1992: Feeding preference experiments using epicuticular wax extractions by greenhouse whitefly. J. Beijing Normal Univ. (Nat. Sci.) 28: 57-61.

McCauley G.W., Margolies D.C. \& Reese J.C. 1990: Feeding behaviour, fecundity and weight of sorghum- and corn-reared greenbugs (biotype E) on corn. Entomol. Exp. Appl. 55: 183-190.

Montllor C.B. \& TJallingil W.F. 1989: Stylet penetration by two aphid species on susceptible and resistant lettuce. Entomol. Exp. Appl. 52: 103-111.

Ponti O.M.B. De, Romanow L.R. \& Berlinger M. 1990: Whitefly-plant relationships: plant resistance. In: Gerling D (ed.): Whiteflies: Their Bionomics, Pest Status and Management. Intercept, UK, pp. 91-106.
Romanow L.R., Ponti O.M.B. de \& Mollema C. 1991: Resistance in tomato to the greenhouse whitefly: analysis of population dynamics. Entomol. Exp. Appl. 60: 247-259.

SCHOONHOVEN L.M., JERMY T. \& LOON J.J.A. VAN 1998: InsectPlant Biology: from Physiology to Evolution. Chapman \& Hall, London, 409 pp.

Spiller N.J., Koendera L. \& Tuallingil W.F. 1990: Xylem ingestion by aphids - a strategy for maintaining water balance. Entomol. Exp. Appl. 38: 187-193.

TIALLINGII W.F. 1988: Electrical recording of stylet penetration activities. In: Minks A.K. \& Harrewijn P. (eds): Aphids, their Biology, Natural Enemies and Control, Volume B. Elsevier Science Publishers B.V., Amsterdam, pp. 95-108.

Vet L.E.M., Lenteren J.C. van \& Woets J. 1980: The parasitehost relationship between Encarsia formosa (Hymenoptera: Aphelinidae) and Trialeurodes vaporariorum (Homoptera: Aleyrodidae). IX. A review of the biological control of the greenhouse whitefly with suggestions for future research. $J$. Appl. Entomol. 90: 26-51.

WALKER G.P. 1985: Stylet penetration by the bayberry whitefly, as affected by leaf age in lemon, Citrus lemon. Entomol. Exp. Appl. 39: 115-121.

WALKER G.P. 1988: The role of leaf cuticle in leaf age preference by bayberry whitefly (Homoptera: Aleyrodidae) on lemon. Ann. Entomol. Soc. Am. 81: 365-369.

WALKER G.P. \& ZAREH N. 1990: Leaf age preference for oviposition by three species of whitefly on lemon. Entomol. Exp. Appl. 56: 31-45.

XU R.M. \& Zhang L.Y. 1991: Functional relationship between pest abundance, plant physiology and yield as exemplified by the greenhouse whitefly, Trialeurodes vaporariorum Westw. (Hom., Aleyrodidae) - An approach on injury threshold and damage threshold. J. Appl. Entomol. 112: 370-381.

Xu R.M. 1994: Plant preference of the greenhouse whitefly. $J$. Beijing Normal Univ. (Nat. Sci.) 30: 125-129.

Zhang L.Y., Guan Z.H. \& Xu R.M. 1987: Studies on the population dynamics of greenhouse whitefly (Trialeurodes vaporariorum Westw.) and its influences on the physiological and biochemical characteristics of cucumber plants. Acta Ecol. Sinica 4: 339-348.

Received February 3, 2000; revised November 9, 2000; accepted January 5, 2001 